\title{
Irradiation Effect on Photodegradation of Pure and Plasticized Poly (4-Methylstyrene) in Solid Films
}

\author{
Saria A. Al Safi, Thanaa M. Al Mouamin, Wadhah N. Al Sieadi, Khalid E. Al Ani* \\ Department of Chemistry, Faculty of Science, Baghdad University, Baghdad, Iraq \\ Email: ${ }^{*}$ khalidalani44@yahoo.com, ${ }^{*}$ khalid7@hu.edu.jo
}

Received 22 January 2014; revised 3 March 2014; accepted 18 March 2014

Copyright (C) 2014 by authors and Scientific Research Publishing Inc.

This work is licensed under the Creative Commons Attribution International License (CC BY). http://creativecommons.org/licenses/by/4.0/

(c) (i) Open Access

\begin{abstract}
The photodegradation of irradiated thin films of poly (para-methylstyrene) with $265 \mathbf{n m}$ radiations in the presence of airand as a function of irradiation time has been studied using $U V$-VIS, fluorescence and FT-IR Spectroscopic techniques. The influence of phthalate and terephthalate plasticizers on stability of poly (para-methylstyrene) towards irradiations was also investigated. Blending with phthalate plasticizers was found to cause a higher efficiency of photodegradation than that obtained in doping with terephthalate plasticizers. The intensity of absorption was also found to increase with time of irradiation and in change in the shape of the spectra at longer wavelength, thus indicating a possibility of photodegradation of polymer chains. The analysis of the FT-IR spectra of the irradiated and non-irradiated samples, shows a predominant absorption associated with carbonyl compounds with $1740 \mathrm{~cm}^{-1}$. In addition, the observed increase in the intensities of the carbonyl and hydroxyl regions of the FT-IR spectra, have provided an evidence for the photodegradation as well as photo-oxidation of polymeric chains. The presence of the plasticizer in the polymer backbone was found to accelerate the photodegradation of polymeric chains.
\end{abstract}

\section{Keywords}

Excimer Fluorescence, Photodegradation Kinetics, Phthalate Plasticizers, Poly (Para-Methylstyrene)

\section{Introduction}

The effect of UV irradiation on stability of polystyrene has been studied in details by several workers [1]-[6],

"Corresponding author.

How to cite this paper: Al Safi, S.A., Al Mouamin, T.M., Al Sieadi, W.N. and Al Ani, K.E. (2014) Irradiation Effect on Photodegradation of Pure and Plasticized Poly (4-Methylstyrene) in Solid Films. Materials Sciences and Applications, 5, $300-315$. http://dx.doi.org/10.4236/msa.2014.55036 
and the mechanisms of photodegradation reactions have been established. Several studies have also been carried out for photodegradation of substituted polystyrene and were found to be of interest for both the theoretical aspects of photo stability and the preparation of new polymers [7]-[12]. During irradiation of polymeric chains in presence of air, excited chromophores are formed followed by other processes, such as chain scission, photooxidation and cross-linking take place [13]-[19]. The interaction of UV-radiations with polymeric chromophores in presence of air resulted in the formation free radicals. The chemical structure of substituted vinyl benzene is susceptible to photodegradation through the formation of oxyradicals when exposed to UV irradiation [14] [15]. The quantum energies associated with irradiated light in the UV region are sufficient to break many chemical bonds present in the polymer chromophores [20].

The mechanism of polystyrene (PS) photodegradation in solid films depends upon the mobility of free radicals in polymeric matrix, and their bimolecular recombination [3]. Free hydrogen radicals diffuse very easily through the polymer matrix, and combine in pairs or abstract hydrogen atoms from polymer chromophores. Phenyl radicals have limited mobility and may abstract hydrogen from the near surroundings, or combine with either a polymer radical in the vicinity, or with hydrogen radical [21] [22]. The photo-oxidation mechanism of PS chromophores in solid films is dependent upon the rate of oxygen diffusion into the polymer matrix, and to the formation of charge transfer complexes between polymer chromophores and oxygen molecules [23]. The rate of photo-oxidation is dependent upon the reactivity of oxygen molecules with the formed radicals in polymeric matrix. A combination of these formed macro-radicals may lead to cross-linking.

Photo-oxidation of polystyrene chromophores occurs when irradiated at $(\lambda=300 \mathrm{~nm})$ under atmospheric oxygen [24] [25], and a number of different photoproducts were reported. Hydroperoxides, carbonyl and hydroxyl compounds were the main products which resulted from the photo-oxidation of PS films [3]-[17]. Different structures have also been reported on the bases of IR and UV-visible analysis [25] [26]. Photodegradation of substituted polystyrenes (SPS) is rather a complicated issue. A number of different photoproducts are formed, and a wide variety of mechanisms have been proposed. The substituted group in the styrene chromophores plays an important role in the mechanism of photo-oxidation and photodegradation reactions [27] [28].

On the other hand, polymeric additives were found to accelerate the radiation-induced degradation of polystyrene and substituted polystyrene films [6]-[12]. It was reported that the photo-stability of PS was reduced by the addition of bromine containing flame retardant, and appeared to depend upon the chemical structure of the polymeric additives [29]. For PS containing carbonyl group, it was found that the photodegradation increases with increasing in irradiation time. The changes in the average molecular weight in photo-oxidized PS were produced as consequences of chain dissociation by Norrish Type II reaction [30]. It was also found that the photo-stability of SPS was reduced by blending with phthalates and terephthalates plasticizers [31]. Phthalate plasticizers were more efficient in the increase in the photodegradation of irradiated polymeric chromophores in solid films [11] [12].

In the present work, the photodegradation of irradiated poly (4-methylstyrene) films, and the effects of blending with phthalates and terephthalates plasticizers on the photo-stability were investigated with the following aims:

1) To investigate the possible influence of ring substitution on the mechanism of photochemical reaction of irradiated poly (4-methylstyrene) (PMS) films, and also to compare its photo-stability with that of polystyrene and other substituted polystyrene.

2) To study the effect of blending PMS with phthalates and terephthalates plasticizers on the photo-stability of PMS films and to select the best polymeric additive that can cause less photodegradation on the irradiated polymeric films.

3) To apply Al Ani-Hawi relation [11], in order to evaluate some kinetic parameters, such as photo quenching rate constant, and quenching efficiencies of irradiated pure and blended polymer films.

The photodegradation processes of the exposed polymer films for different intervals of time have been characterized by UV-visible, fluorescence and FT-IR spectroscopic techniques. The efficiency of photodegradation of pure film is compared with that of blended polymer films.

\section{Materials and Methods}

\subsection{Materials}

The sample of poly (4-methylstyrene) was supplied by Across-Organics with high purity. Only spectroscopic 
grade dichloroethane (DCE) was used in casting of solid films. It was found to give no detectable absorptionin range (250 - $400 \mathrm{~nm})$. It was purchased from Fluka GMBH and was used as received. The used plasticizers aredimethyl terephthalate (DMT), diethyl terephthalate (DET), dioctyl terephthalate (DOT), dibutyl phthalate (DBP) and dioctyl phthalate (DOP). These were of high purity of about (99.8\%), and were purchased from Across-Organics and found to give no detectable absorption in rang $260-400 \mathrm{~nm}$.

\subsection{Preparation of Plasticized Polymeric Solid Films}

PMS thin films with thickness of approximately $0.02 \mathrm{~mm}$ were prepared by solution casting of $20 \mathrm{wt} \%$ polymer in DCE on a spectroscopic window (quartz plate of $1.0 \mathrm{~mm} \times 20 \mathrm{~mm}$ diameter). Moreover, about $0.02 \mathrm{~mm}$ thick PMS-plasticizer films, containing different wt \% plasticizers were prepared by solution castingof $20 \mathrm{wt} \%$ polymer + added plasticizer, in DCE solvent. These films were used as to gain better insight into thepossibility of photodegradation of the polymer during irradiation. The films were dried in a vacuum oven at $293 \mathrm{~K}$ for 6 hours, as to ensure the complete removal of solvent traces [10].

\subsection{Absorption and Fluorescence Spectra Measurements}

The UV absorption spectra for PMS solid films were recorded before and immediately after UV irradiation with a Cary 100 Bio UV-visible Spectrophotometer at $298 \mathrm{~K}$.

Fluorescence spectra were recorded on JASCO-FP 6500 Spectrofluorometer for each of the prepared samples. The parameters were constant for all measurements, and the excitation wavelength was $265 \mathrm{~nm}$. The emission wavelength range was $270-500 \mathrm{~nm}$, and all fluorescence spectra for the solid films were obtained using athermostated solid sample holder at $298 \mathrm{~K}$.

\subsection{Irradiation of Polymeric Solid Films}

PFS isomers solid films were exposed to different intervals of irradiation time in air, from (0.0 - 3 hours), using a JASCO-Spectrofluorometer with a built in Hydrogen-Xenon lamp (6808 - J007A model number ESC-333), and supported with monochromator of holographic grating with 1800 groves $/ \mathrm{mm}$. Solid films were exposed to the same rate of irradiation intensity.

\subsection{Measurements of FT-IR-Spectra}

The Fourier transform infrared spectroscopy system that was employed in this work was NICOLET-MAGNA$I R$-560 spectrometer, while the transmission mode was employed in these measurements. The working wavenumber range of the spectrometer was from 4000 to $500 \mathrm{~cm}^{-1}$, with a resolution of $4 \mathrm{~cm}^{-1}$. The FT-IR spectra were recorded for the irradiated and the non-irradiated films, whereas the transmittance wasplotted as function of the wavenumber.

\section{Results and Discussion}

\subsection{Effect of Irradiation on the Absorption Spectra of Pure and Blended Poly (4-Methylstyrene) Solid Films}

Poly (4-methylstyrene) was found to absorb radiation in the UV-region of (250 - $280 \mathrm{~nm})$, similar to those of polystyrene and substituted polystyrene. The small changes in the shape of the absorption spectra may be attributed to the chemical structure and the position of substitution in phenyl ring [6]. The effect of radiation energy on the efficiency of photochemical processes in films of pure and blended PMS films with $4.0 \%$ of phthalates and terephthalates plasticizers were studied by their absorption spectra. The increase in irradiation times of pure PMS film, showed a gradual increase in the intensity of the absorption spectra as well as a small change in the shape of the spectra, as shown in Figure 1.

The short UV-radiation has sufficient energy to cleave the bond in the polymeric chains with production of free radicals. The presence of oxygen distinctly increased the efficiency of absorption and accelerates the photooxidation of polymer chains, which led to the formation of macroradicals species [13]. Radicals thus formed, may recombine to give conjugated $\pi$-electron system. The conjugated species are usually presumed to be poly phenyl cross linked products, which resulted from phenyl radicals recombination after direct bond scissions [32]. 


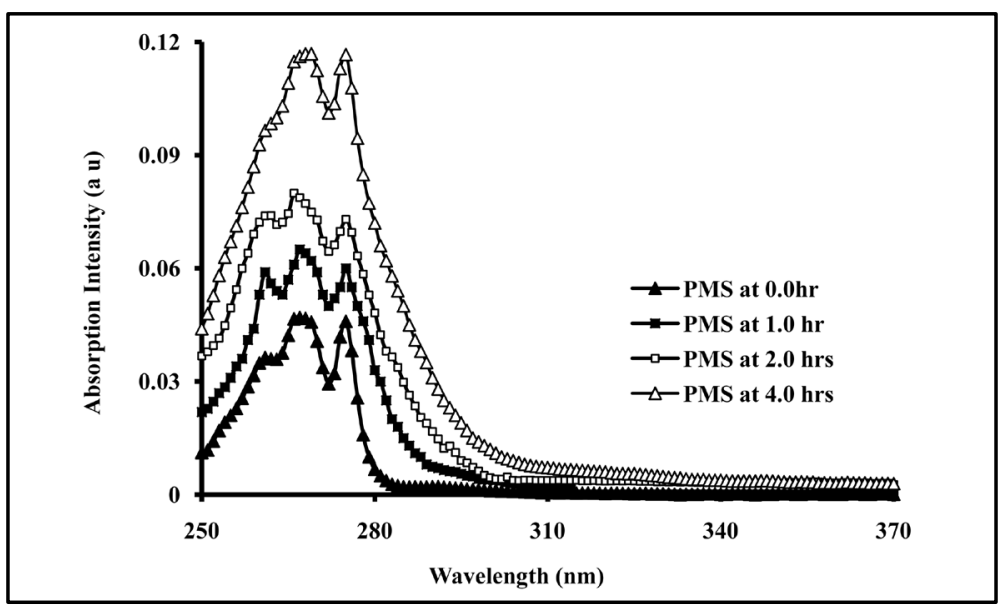

Figure 1. UV-Absorption spectra of, non-irradiated and irradiated for 0.0, 1, 2 and 4 hrs of PMS film at $\left(\left(\lambda_{\text {ext }}=265 \mathrm{~nm}\right)\right.$.

The absorption spectra of irradiated PMS films doped with 4.0 \% DBP and DOP for different intervals of time are shown in Figure 2(a) and Figure 2(b).

As can be seen from Figure 2(a) and Figure 2(b), the increase in irradiation times of blended polymer shows an increase in the intensity of the absorption spectrum, and increase with the increase in the amount of blended plasticizers as well as the appearance of new broad band at longer wavelength $(284-310 \mathrm{~nm})$. The broad band has no clear maximum and its intensity increase with the increase of doped plasticizers. The formation of a broad band and the increase in its intensity with increasing of exposure time are most likely due to; first, the formation of new chromophores resulting from the photo-oxidation of polymeric chains and, second, to the possible interaction between added plasticizer molecules and the excited state chromophores. It was reported that irradiated polystyrene films showed absorption by photoproducts at about $350 \mathrm{~nm}$ during photodegradation processes [33]. The photoproducts resulting from the reaction were involving benzene-ring opening photo-oxidation in polystyrene chromophores [22]. The presence of plasticizer molecules in the irradiated polymer backbone may also accelerate the photochemical processes in the polymeric chains [16]. The effect of irradiation of PMS films doped with 4.0\% of DMT, DET and DOT plasticizers for 4.0 hours is shown in Figure 3.

As cab be seen from Figure 3, the same observation were noticed as in the case of the effect of doped phthalates plasticizers, a formation of broad band at longer wavelength as well as decreasein the intensity of the absorption band. In general phthalate plasticizers showed a higher efficiency of photodegradation in comparison with that caused by terephthalate plasticizers.

\subsection{Effect of UV-Irradiation Time on Fluorescence Spectra of Pure and Blended PMS Films with DMT, DET, DOT, DBP and DOP Plasticizers}

The study of the photodegradation of para-substituted polystyrene receives a considerable attention, mainly due to their industrial importance [34]-[40]. However, the photodegradation of some substituted polystyrene has been studied extensively but no work on photodegradation of plasticized PMS by fluorescence technique has been reported in solid films. The fluorescence spectrum is composed from a minor band as monomer fluorescence and a major band at longer wavelength as excimer fluorescence. Blending of PMS films with phthalates and terephthalates plasticizers would result in, first, quenching of both excimer and monomer emissions, and second, an increase in the intensity of a new fluorescence band at longer wavelength. Different percentages of these plasticizers $(1.0 \%-4.0 \%)$, were used in blending of PMS films, and irradiated for several intervals of time by the same source of light with ( $\lambda_{\text {ext }}=265 \mathrm{~nm}$ ), and under the same conditions.

The fluorescence spectra were obtained for pure PMS film, photo-irradiated for $(0.0$ - $150 \mathrm{~min})$ and are shown in Figure 4. Irradiation of the PMS film at different exposure time was accompanied by the gradual quenching in the intensity of the excimer band, as well as a small red shift in the excimer fluorescence band (313 - $315 \mathrm{~nm}$ ). It is more likely that this red shift occurs as result of photodegradation of the polymeric chains, and can be attributed to the formation of conjugated double bonds along the polymer chain during the photodegradation by hy- 


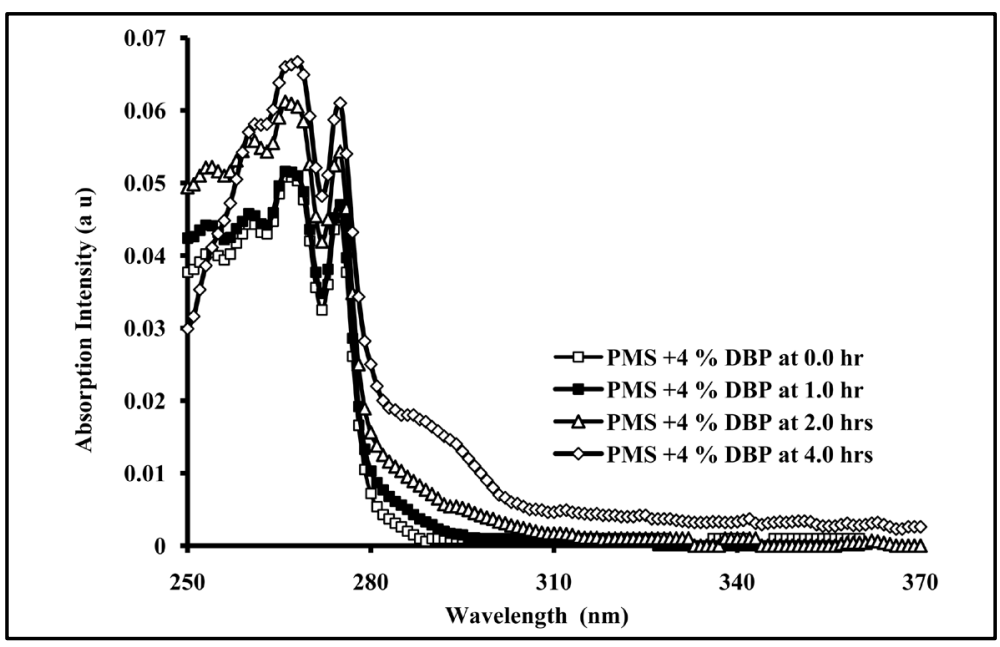

(a)

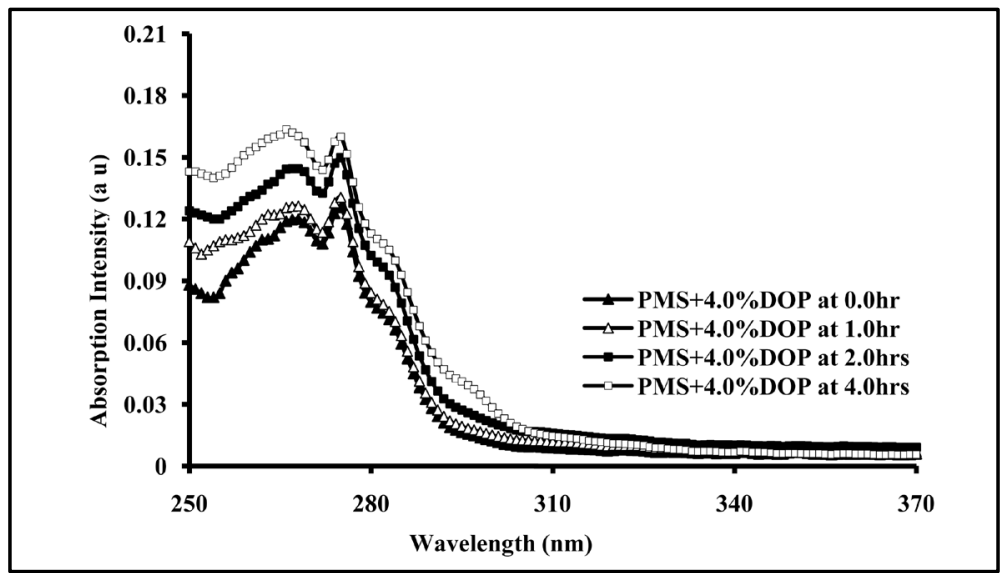

(b)

Figure 2. Absorption spectra of PMS blended with; (a) 4.0\% Dibutyl phthalate (DBP), and (b) 4.0\% Dioctyl phthalate (DOP), irradiated for 0.0, 1.0, 2.0, and 4.0 hrs.

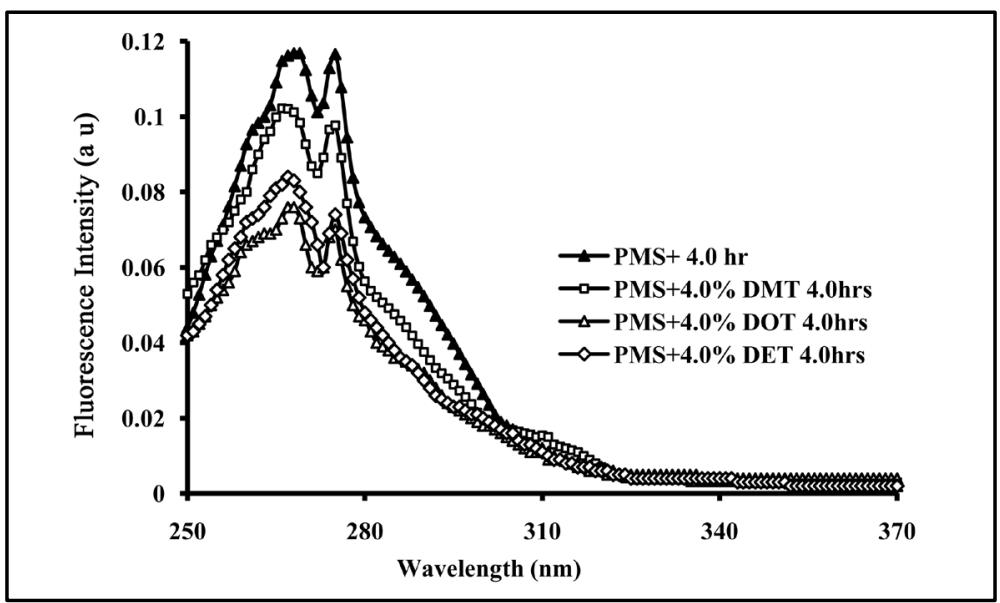

Figure 3. Absorption spectra of PMS blended with, 4.0\% Dimethyl terephthalate, $4.0 \%$ Diethyl terephthalate and $4.0 \%$ dioctyl terephthalate, irradiated for 4.0 hours at $\left(\lambda_{\text {ext }}=265 \mathrm{~nm}\right)$. 


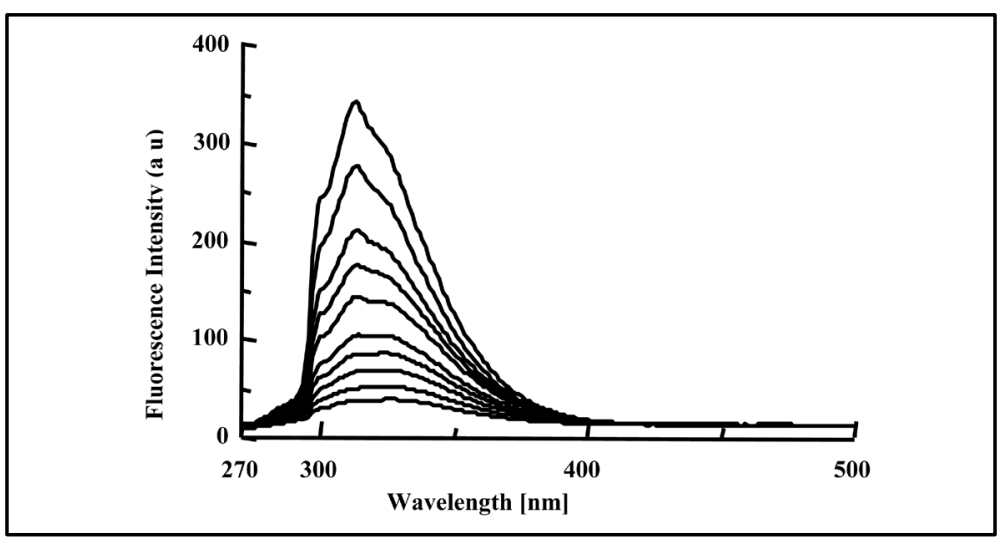

Figure 4. Fluorescence spectra of irradiated pure PMS films at 0, 5, 10, 20, 40,

$60,80,100,120$ and $150 \mathrm{~min}$, spectra are from top to bottom, $\left(\lambda_{\mathrm{ext}}=265 \mathrm{~nm}\right)$.

drogen abstraction process [41] [43].

The shift in the excimer fluorescence band of the irradiated PMS film is in good agreement with that reported with irradiated PS [14] and poly (4-methoxystyrene) [11]. Tovborg and Kops [43] pointed out that quenching of polymeric emission might be attributed to the energy transportation of the oxides formed by the photo-oxidation of polymeric chromophores, or to the quenching effect of the formed peroxide formed during UV-irradiation.

The fluorescence spectra of blended PMS films with 4.0\% DMT, DET, DOT, DBP, and DOP plasticizers have slightly some modification to that of pure film. As can be seen from Figure 5(a) and Figure 5(b), for the PMS film blended with $4.0 \%$ DOP and DBP respectively, the quenching efficiency in the intensity of the fluorescence band was increased by the increase in irradiation time.

The blending of PMS film with phthalate plasticizers (4.0\% DOP and 4.0\% DBP), shows only excimer and monomer fluorescence bands and no exciplex emission was observed upon the increase in the percentage off added plasticizers. Most likely, the formed energy transfer complex formed between the polymer chromophore and the plasticizer molecule is not stable enough to give exciplex fluorescence emission.

The gradual decrease in the monomer and excimer fluorescence bands of blended PMS films at different intervals of exposure time was accompanied by the increase in the fluorescence intensify of new broad band without clear maxima at longer wavelength $(380-500 \mathrm{~nm}$ ), as clearly seen by blending with DOP plasticizer. We believe that this broad band appeared as result of the formation of new compounds from the photo-oxidation and photodegradation processes of irradiated PMS, indicating the possibility of formation of polyene unitstructures and possibly other oxygen containing compounds. Based on the work of Geuskens et al. [22] relevant to photodegradation of PS, the fluorescence bands of 362, 425 and $477 \mathrm{~nm}$ corresponded to polyene unit structure and were defined by ( $\mathrm{n}=1,2$ and 3) respectively. As can be seen from Figure 5(a), although the formation of new broad band at longer wavelength has no clear maxima, but the position was not far from the range (362 $477 \mathrm{~nm}$ ), indicating the possibility of formation of polyene unit structures during the irradiation of polymer chromophores [29].

Blending of PMS films with terephthalates plasticizers (DMT, DET and DOT) showed some different behaviors from the blending with phthalate plasticizers. As can be seen from Figures 6(a)-(c), for blending PMS films with $4.0 \%$ of DMT, DET and DOT respectively, the increase in exposure time of the blended films caused a decrease in the intensity of the polymer fluorescence band and the appearance of a broad band at longer wavelength.

The formation of a new fluorescence band at longer wave length of $\lambda_{\max }=352 \mathrm{~nm}$ in blending with DMT, $\lambda_{\max }$ $=334 \mathrm{~nm}$ for blending with DET and $\lambda_{\max }=356 \mathrm{~nm}$ for blending with DOT, were found to increase their intensity with the increase in the amount of blended terephthalate plasticizers. The appearance of these new fluorescence bands may be attributed to the formation of excited complex from the excited polymer chromophores and the ground state terephthalate molecules [44]. Exciplex conformations gave fluorescence emission at longer wavelength, and found to decrease in their intensities with increase in irradiation exposure time. On the other hand, the increase in irradiation time showed the formation of small new fluorescence band at longer wavelength (420 - $500 \mathrm{~nm}$ ), and found to increase its intensity with the increase in irradiation time. We believe that this 


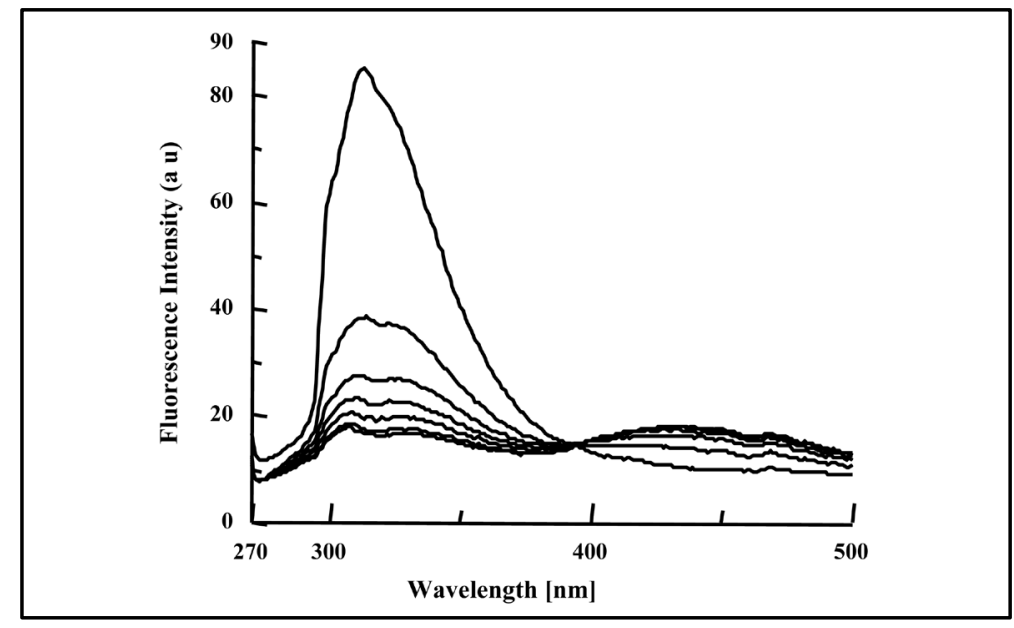

(a)

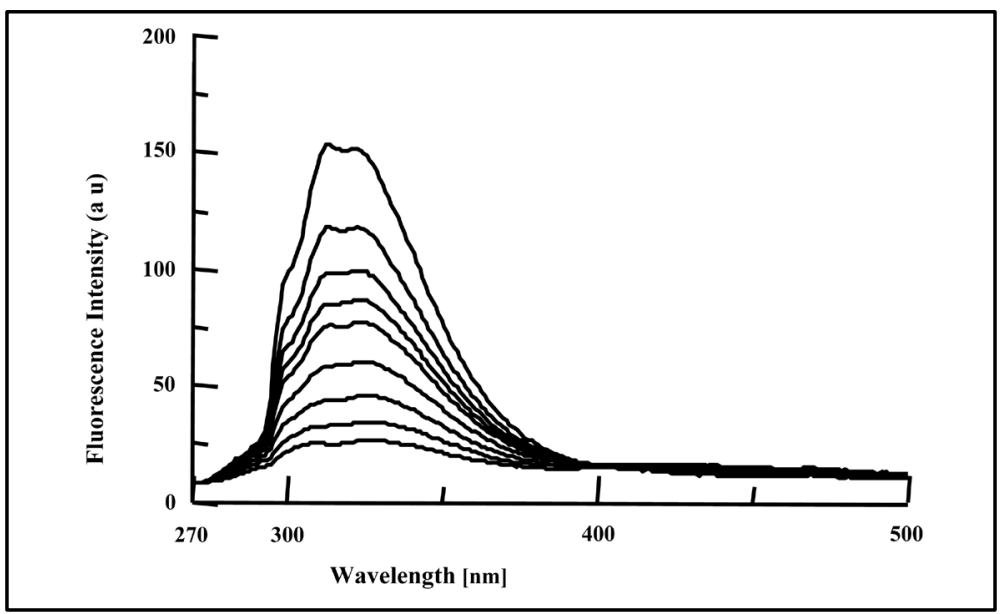

(b)

Figure 5. Fluorescence spectra of irradiated blended PMS film with, (a) $4.0 \%$ DOP at $0,10,20,30,40,50$ and $60 \mathrm{~min}$ (from top to bottom); (b) $4.0 \% \mathrm{DBP}$ at $0,5,10,15,20,30,40,50$ and $60 \mathrm{~min}$, spectra are from top to bottom.

broad band appeared as result of the formation of new compounds from the photo-oxidation and photodegradation processes of irradiated PMS, indicating the possibility of formation of polyene unit structures and possibly other oxygen containing compounds.

\subsection{Kinetics and Mechanism of Photodegradation of Pure and Blended PMS Solid Films}

The effects of blended amount of the added plasticizers and the increase in irradiation time on the fluorescence intensity of PMS films were studied as function of irradiation time.

Al Ani and Hawi [11] have formulated a new mathematical relation that can be used to study the kinetic treatments to the decrease of fluorescence quenching of PMS film by the increase in the amount of added plasticizers and by the increase in irradiation times at room temperature.

The ratio of $I_{[E X]^{*}}^{o} / I_{[E X]^{*}}$ was found to increase by the increase in irradiation time to polymeric film. $I_{[E X]^{*}}^{o}$ is the intensity of excimer fluorescence of pure or blended polymer at zero time of irradiation, whereas, $I_{[E X]^{*}}$ is the intensity of excimer emission of pure or blended polymer at different intervals of exposure time.

$$
\left(\frac{I_{E X}^{o}}{\boldsymbol{I}_{E X}}\right)^{*}=1+\left\{\left(k_{P Q}^{\prime}\right)(A)\right\}(t)
$$




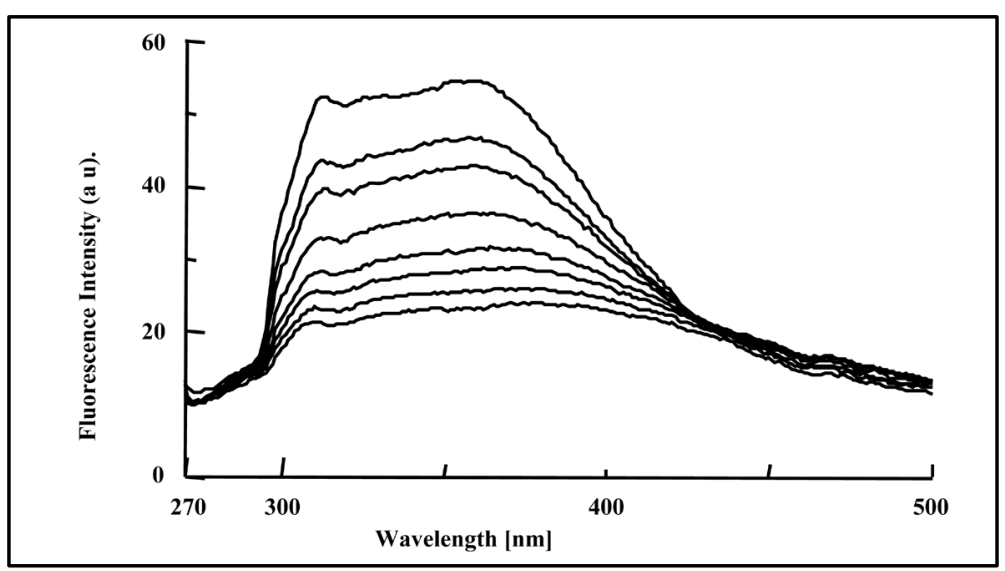

(a)

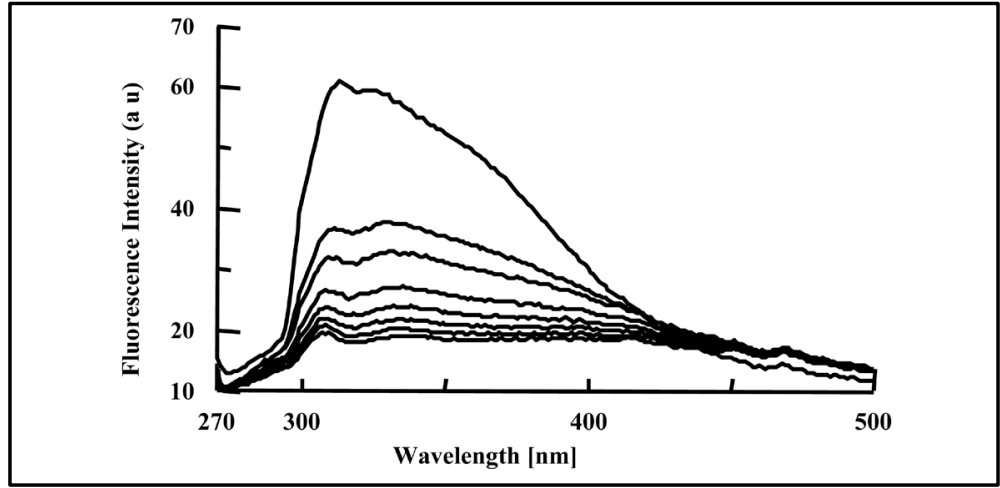

(b)

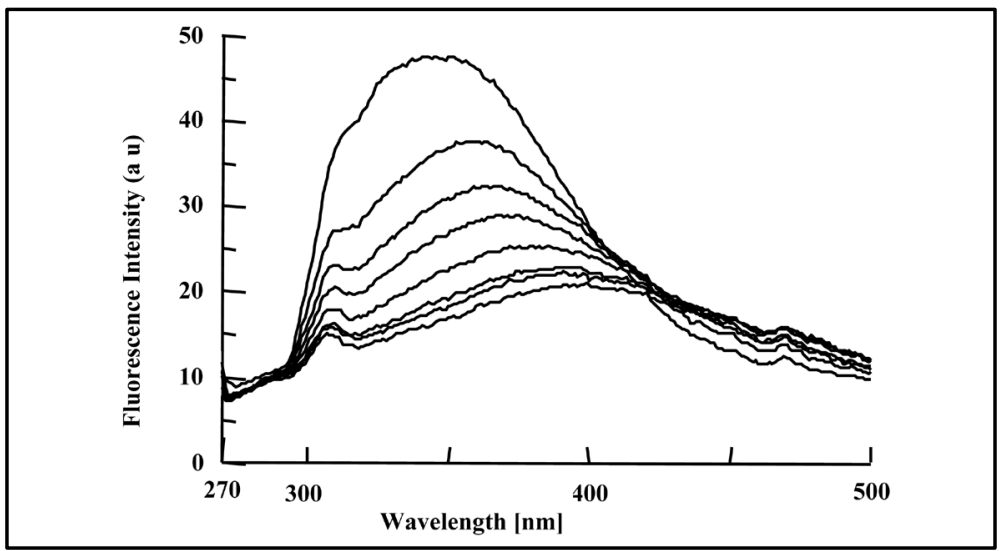

(c)

Figure 6. Fluorescence spectra of irradiated doped PMS films with, (a) 4.0\% DMT; (b) 4.0\% DET and (c) 4.0\% DOT at irradiation times, 0, 10, 20, 30, 40, 50, 70 and $90 \mathrm{~min}$, (spectra are from top to bottom).

where $[A]=$ number of (photons/s) absorbed by polymeric chromophores.

$t=$ time of irradiation in $\mathrm{s}$.

$k_{P Q}^{\prime}=$ rate constant. And,

$$
\left(\frac{I_{E X}^{o}}{I_{E X}}\right)^{*}=1+\left(k_{P Q}\right)(t)
$$


where the quenching rate constant $k_{P Q}$ equal to:

$$
k_{P Q}=\left\{\left(k_{P Q}^{\prime}\right)(A)\right\}
$$

In the photo-quenching processes, if we assume that the number of photons released from the light source and absorbed by polymer chromophores is constant (A), then, according to Equation (2), $I_{[E X]^{*}}^{o} / I_{[E X]^{*}}$ 一 values were plotted against time of irradiations (t). From the plots, the photo-quenching rate constant $\left(\boldsymbol{k}_{P Q}\right)$ values and $I_{[E X]^{*}}^{o} / I_{[E X]^{*}}$ ratios were calculated and were used to estimate the efficiency of photo quenching and photodegradation processes for pure and blended polymer.The plots of the ratio of excimer fluorescence $I_{[E X]^{*}}^{o} / I_{[E X]^{*}}$ against the different irradiation time of blended PMS films with 1.0\%, 2.0\%, 3.0\% and 4.0\% of DBP and DOP are presented in Figure 7.

As can be seen in Figure 7, an increase in the amount of added phthalate plasticizers resulted in an increase in the degradation ratio of $I_{[E X]^{*}}^{o} / I_{[E X]^{*}}$ with the increase of exposure time. On the other hand, an increase in the amount of added DBP resulted in an increase in the photo-quenching rate constant $\left(k_{P Q}\right)$ whereas increase of added DOP in the irradiated polymer film resulted in a decrease in the photo-quenching rate constant. The same results were obtained in the photodegradation of blended Poly (4-tert-butylstyrene) films [9]. Blending with DBP showed a higher photo quenching rate constant than in blending with other phthalate or terephthalate plasticizers.

The increase in the excimer fluorescence ratio $I_{[E X]^{*}}^{o} / I_{[E X]^{*}}$ with the increase in irradiation time, and the increase in the photo-quenching rate constant $\left(k_{P Q}\right)$ with the increase in irradiation time, indicates that fluorescence quenching by added plasticizers may be accompanied by photochemical reaction in the polymer backbone. Also, there is a possible reaction between the free radicals formed by the chain scission of polymeric chains and the added plasticizer molecules which increase the efficiency of the quenching process.It was reported that chain scissions and changes in the molecular weight distribution, as well as, photo-oxidation process that were interpreted as a reaction involving benzene ring-opening photo-oxidation were also the processes that resulted from irradiation of PS in the presence of polymeric additives [45] [46].
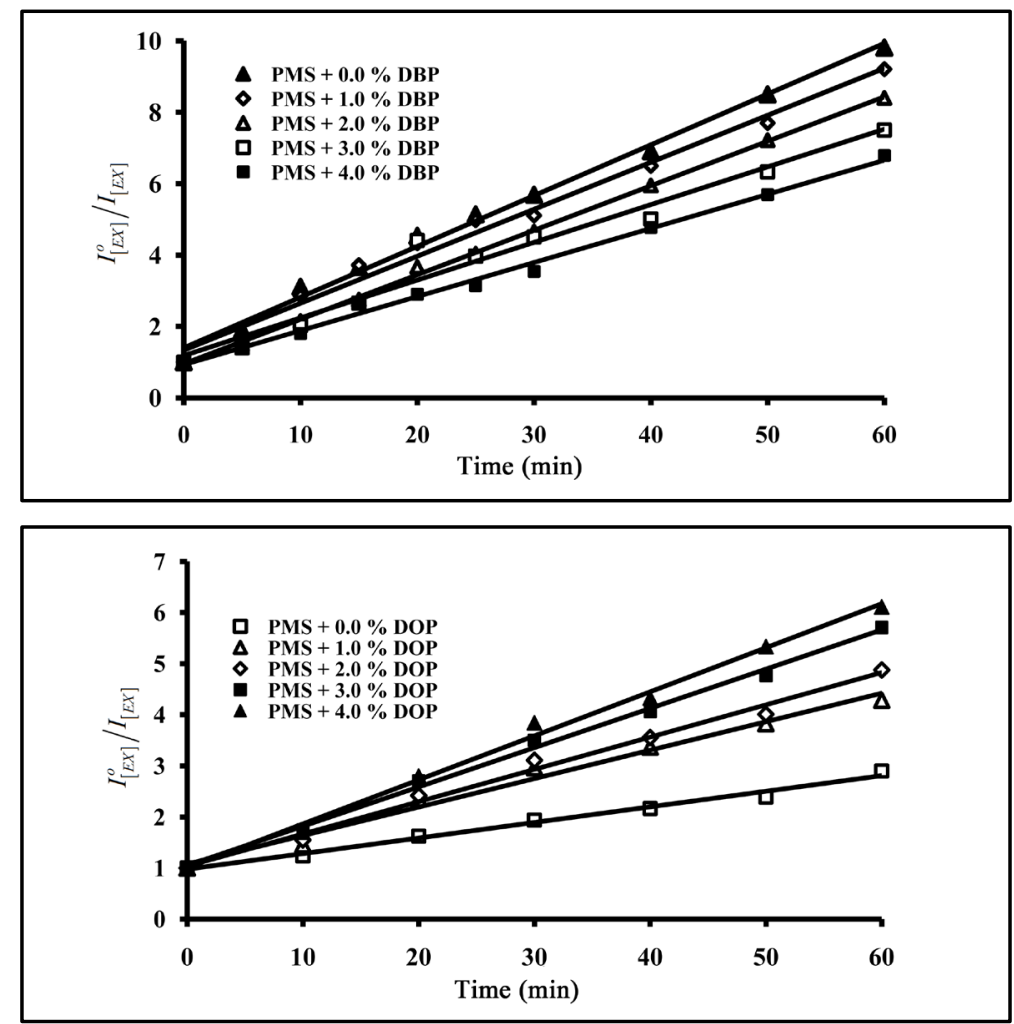

Figure 7. Effect of added mass percent of DBP and DOP on excimer fluorescence quenching of blended PMS films at different irradiation times. 
In an earlier work, it was reported that the photo—stability of substituted polystyrene was reduced by the addition of polymeric additives, and to depend on both, the chemical structure of the para-substituted group and also to the bulkiness of the plasticizer molecule [7].

As can be seen in Figure 8, an increase in the amount of added terephthalate plasticizers resulted in an increase in the degradation ratio of $I_{[E X]^{*}}^{o} / I_{[E X]^{*}}$ with the increase of exposure time. From Figure 7 and Figure 8, the photo quenching rate constants in blending with phthalate plasticizers are higher than that obtained in blending with terephthalates plasticizers. On the other hand, blending with DBP gave higher values of photo quenching rate constant than that obtained by DOP. The order of increase in photo quenching by blending with terephthalates plasticizers is DOT, DET and DMT.

From the data in Figure 7 and Figure 8, and by applying the Al Ani-Hawi relation where the ratio $\left(I_{[E X]^{*}}^{o} / I_{[E X]^{*}}\right)$ was plotted against different intervals of the exposure time, from the slope of the obtained lines, $\left(k_{P Q}\right)$ values were calculated for PMS blended with different percentages of DMT, DET, DOT, DBP and DOP, and are presented in Table 1.
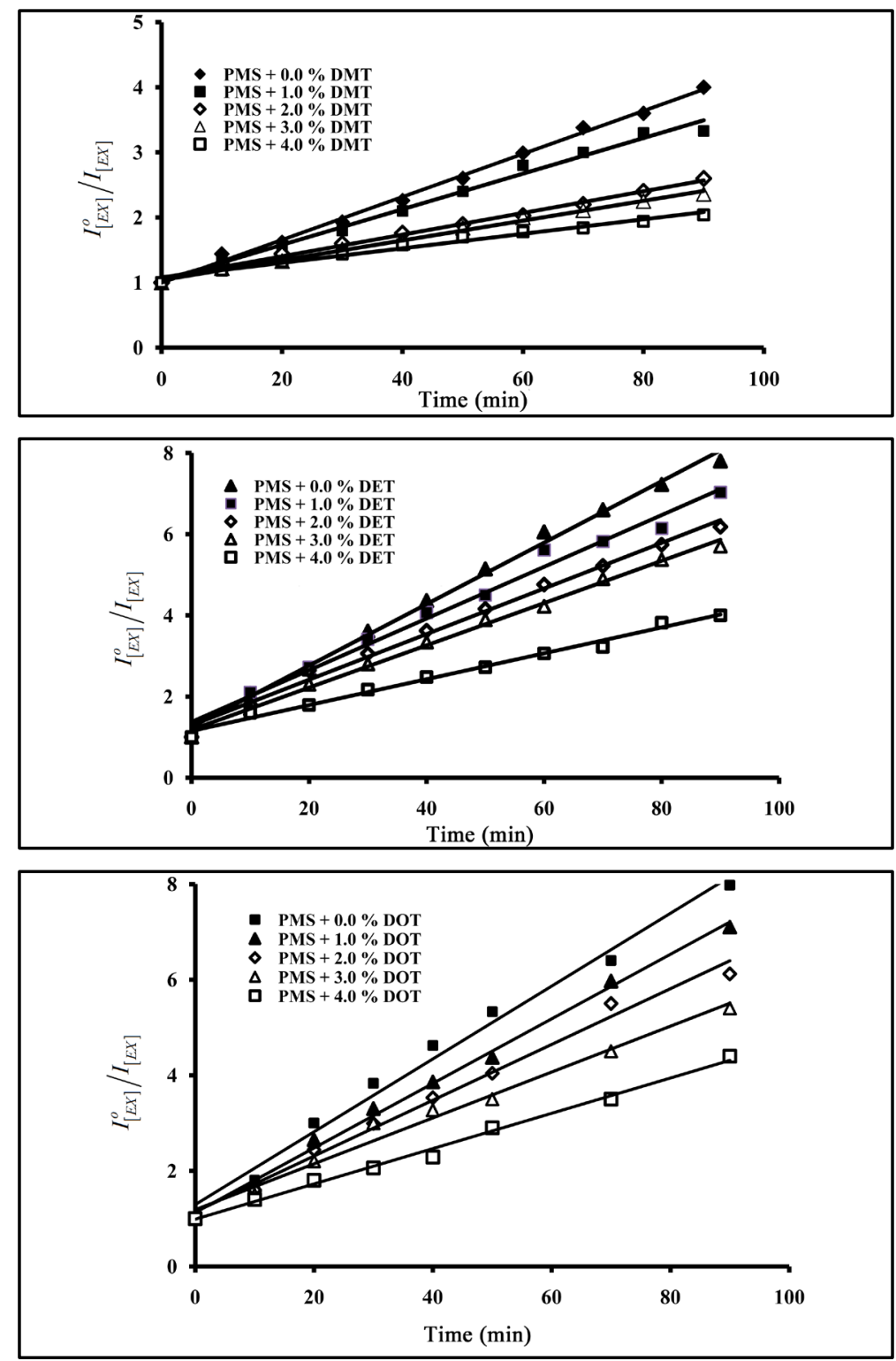

Figure 8. Effect of added mass percent of DMT, DET and DOT on excimer fluorescence quenching of blended PMS films at different irradiation time. 
Table 1. Relative Intensities of the ratio $\left(I_{[E X]^{*}}^{o} / I_{[E X]^{*}}\right)$ and $k_{P Q}$ values for the excimer fluorescence spectra of pure and blended irradiated PMS films.

\begin{tabular}{|c|c|c|c|c|c|}
\hline Polymer Emission & $\lambda_{\max }(\mathrm{nm})$ & Plasticizer \& \% Irradiated & Time (min) & $I_{[E X]^{*}}^{o} / I_{[E X]^{*}}$ & $k_{P Q}$ \\
\hline PMS & 316 & DMT, $0.0 \%$ & 90 & 4.34 & 0.033 \\
\hline PMS & 316 & DMT, $1.0 \%$ & 90 & 3.33 & 0.027 \\
\hline PMS & 316 & DMT, $2.0 \%$ & 90 & 2.61 & 0.017 \\
\hline PMS & 317 & DMT, $3.0 \%$ & 90 & 2.36 & 0.015 \\
\hline PMS & 317 & DMT, $4.0 \%$ & 90 & 2.04 & 0.011 \\
\hline PMS & 317 & DET, $0.0 \%$ & 90 & 7.80 & 0.076 \\
\hline PMS & 319 & DET, $1.0 \%$ & 90 & 7.03 & 0.064 \\
\hline PMS & 320 & DET, $2.0 \%$ & 90 & 6.18 & 0.056 \\
\hline PMS & 321 & DET, 3.0\% & 90 & 5.72 & 0.052 \\
\hline PMS & 321 & DET, $4.0 \%$ & 90 & 4.00 & 0.032 \\
\hline PMS & 317 & DOT, $0.0 \%$ & 90 & 7.90 & 0.076 \\
\hline PMS & 318 & DOT, $1.0 \%$ & 90 & 7.15 & 0.068 \\
\hline PMS & 320 & DOT, $2.0 \%$ & 90 & 6.12 & 0.058 \\
\hline PMS & 320 & DOT, $3.0 \%$ & 90 & 5.40 & 0.048 \\
\hline PMS & 320 & DOT, $4.0 \%$ & 90 & 4.44 & 0.037 \\
\hline PMS & 315 & DBP, $0.0 \%$ & 60 & 9.80 & 0.142 \\
\hline PMS & 315 & DBP, $1.0 \%$ & 60 & 9.21 & 0.132 \\
\hline PMS & 315 & DBP, $2.0 \%$ & 60 & 8.42 & 0.125 \\
\hline PMS & 315 & DBP, $3.0 \%$ & 60 & 7.55 & 0.106 \\
\hline PMS & 316 & DBP, $4.0 \%$ & 60 & 6.79 & 0.096 \\
\hline PMS & 316 & DOP, $0.0 \%$ & 60 & 2.96 & 0.086 \\
\hline PMS & 318 & DOP, $1.0 \%$ & 60 & 4.28 & 0.077 \\
\hline PMS & 319 & DOP, $2.0 \%$ & 60 & 4.87 & 0.063 \\
\hline PMS & 319 & DOP, $3.0 \%$ & 60 & 5.72 & 0.056 \\
\hline PMS & 320 & DOP, $4.0 \%$ & 60 & 6.11 & 0.031 \\
\hline
\end{tabular}

As can be seen from Table 1, blended polymers with the five used plasticizers, gave a higher quenching efficiency than that obtained without blending. In general the para-substituted group in the phenyl ring of the monomer and the structure and bulkiness of the plasticizer molecule play a big role in the photo quenching and stability of plasticized polymers. Furthermore, the stability of polymer chains was found to depend on the above mentioned factors as well as the exposure time. It has been reported previously that the presence of plasticizer molecules in polymer matrix caused lowering in the activation energy during the thermal degradation of (PMXS) films [47], and was attributed to the lowering in the charge transfer character of the excimer conformation. It was also found that the main process resulted from irradiation of blended polymer film in presence of air, were photo-oxidation of polymeric chromophores as well as chain scission and crosslinking [29].

\subsection{FT-IR Spectra for Non-Irradiated and Irradiated Pure and Blended PMS in Solid Films}

In order to confirm the presence of photo degradation in the irradiated pure and blended PMS films with 4.0\% 
DMT, FT-IR spectra were recorded of non-irradiated and irradiated films under atmospheric oxygen, and at 298 K. Figure 9 shows the FT-IR spectra of non-irradiated and irradiated ( 0.0 and $2.0 \mathrm{hrs}$ ) of pure PMS solid film, and were recorded immediately before and after irradiation. The effect of irradiated film caused the increase in the intensity of some absorption bands, and the formation of new bands as a result of the photodegradation and photo oxidation processes of polymeric chains.

It was noted that the most demonstrated trend is the increase of the absorbance bands at $\left(3800-3000 \mathrm{~cm}^{-1}\right)$, and by the formation of new absorption bands corresponding to new compounds resulting from the photodegradation of polymer chains in different regions of the spectra. Several authors have reported the following bands and are found to refer to the following functional groups. The formation of absorption bands in the range (3600 $3400 \mathrm{~cm}^{-1}$ ), are attributed to formation of the hydroxyl group. They are formed only in the presence of air (oxygen) and are probably due to oxidized benzene rings in polystyrene macromolecules [3].

As can beseen in Figure 10, modifications occure in different bands in the FT-IR spectra, the increase of the bands at (2920, 2854 and $\left.1889 \mathrm{~cm}^{-1}\right)$ can be sssigned to the formation of more congugated double bonds as well as the formation of carbony contaning compounds. The irradiated PMS film shows that the photo-oxidation led to the increase in the intensity of absorption of $\left(1442\right.$ and $\left.830 \mathrm{~cm}^{-1}\right)$, which attributed to the increase in the formation of cogugated double bonds as well as the increase in the formation of $(\mathrm{C}=\mathrm{O})$ bonds in the backbone of the plymer. The icrease in the intensity of these band is good indication of the photo-oxidation during irradiation of PMS film.

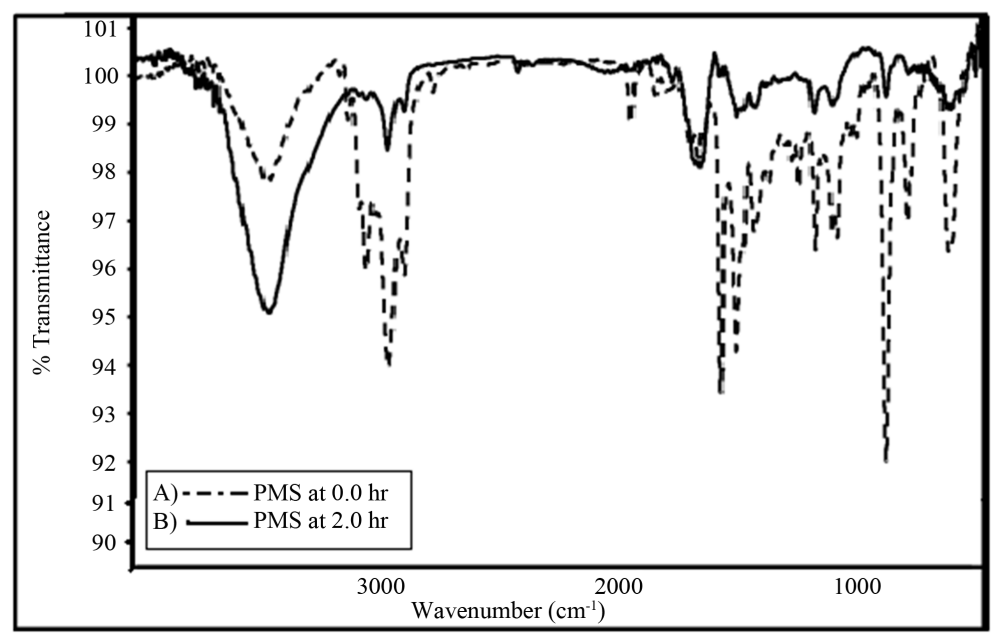

Figure 9. FT-IR spectra of irradiated (solid line) and non-irradiated (dotted line) for $120 \mathrm{~min}$ of PMS film, at $298 \mathrm{~K}$.

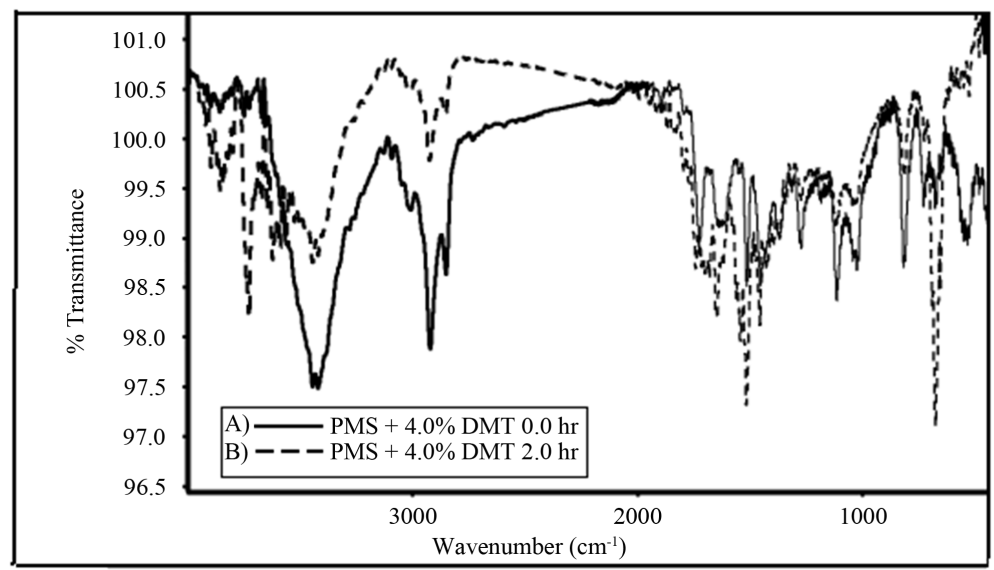

Figure 10. FT-IR spectra of irradiated (dotted line) and non-irradiated (solid line) for 120 min of blended PMS film with 4.0\% DMT, at $298 \mathrm{~K}$. 
The increase of the absorption band around $1714 \mathrm{~cm}^{-1}$, with the increase in irradiation time is evidence of the creation of new photo-oxidation products. However, the interpretation of this band is not simple because of the overlapping of the different types of carbonyl species in the same frequency range. It is generally accepted to attribute the absorption band for $\mathrm{C}=\mathrm{O}$ stretching vibration at $\left(1705-1715 \mathrm{~cm}^{-1}\right)$, to saturated and unsaturated ketones and aldehydes [45] [48], as shown in Table 2.

The other observation in the FT-IR-spectrum is the large increase in the relative absorption in the region (1610 $1028 \mathrm{~cm}^{-1}$ ), in comparison with that of unblended PMS film. This may indicate that there is an increase in the number of $(\mathrm{C}=\mathrm{C})$ that resulted from hydrogen abstraction during chains-scission process.

As can be seen from the FT-IR spectra of irradiated and non-irradiated PMS and blended PMS, modifications occur in different zones of the Spectra. The pure and the blended polymer spectra, recorded after different intervals of time, permit characterizing these modifications in the following points:

1) At high region of the FT-IR spectra, the band at $3440 \mathrm{~cm}^{-1}$, a noticeable increase in the absorption band is observed in doped polymer; on the other hand, a very small decrease was observed in the irradiated polymer that can be ascribed to associate carboxylic acid group [49].

2) In the domain of the $\mathrm{C}=\mathrm{O}$ stretching vibrations, (Figure 9 and Figure 10) of PMS and blended PMS, one observes the appearance of two bands with their maxima at about $1714 \mathrm{~cm}^{-1}$ and $1645 \mathrm{~cm}^{-1}$. The appearance of a new broad band at $1714 \mathrm{~cm}^{-1}$, and the increase in its intensity with increase in irradiation time could be attributed to the formation of oxidation products. The increase in the intensity of the band at $1645 \mathrm{~cm}^{-1}$, may well indicate that aromatic units loose their symmetry throughout the photo-oxidation process.

Table 2. FT-IR-band position in (PMS) and (PMS) blended with 4\% DMT, before and after, 0.0, and 2.0 hrs of irradiation at $\left(\lambda_{\mathrm{ext}}=265 \mathrm{~nm}\right)$.

\begin{tabular}{|c|c|c|c|c|c|}
\hline \multirow{2}{*}{ Polymer } & \multirow{2}{*}{ Band $\left(\mathrm{cm}^{-1}\right)$} & \multicolumn{2}{|c|}{ Time of irradiation } & \multirow{2}{*}{ Type of Vibration } & \multirow{2}{*}{ Intensity } \\
\hline & & $0.0 \mathrm{hr}$ & $2.0 \mathrm{hrs}$ & & \\
\hline PMS & 3446 & 3446 & 3430 & $\mathrm{C}-\mathrm{H}$ stretch in benzene & Decreased \\
\hline PMS & 3014 & ------ & 3014 & & Increased \\
\hline PMS & 2923 & 2924 & 2920 & (C-H), stretching vibration of benzene & Increased \\
\hline PMS & 2854 & 2854 & 2853 & C-H stretch in aldehydes & Increased \\
\hline PMS & 1889 & 1889 & 1889 & $\mathrm{C}=\mathrm{O}$ stretch & Increased \\
\hline PMS & 1602 & 1602 & 1602 & $\mathrm{C}=\mathrm{C}$ stretch & Decreased \\
\hline PMS & 1443 & 1443 & 1446 & $\mathrm{C}=\mathrm{O}$ stretch vibrations, Carboxylic acids-dimeric forms & Increased \\
\hline PMS & 811 & 811 & 811 & Conjugated double bond & Increased \\
\hline PMS & 547 & 547 & 549 & Mono substitution of benzene ring & Decreased \\
\hline $\mathrm{PMS} / \mathrm{DMT}^{\mathrm{a}}$ & 3729 & 3729 & ------ & $\mathrm{C}-\mathrm{O}-\mathrm{C}$ stretching vibration & Disappears \\
\hline PMS/DMT & 3446 & 3446 & 3423 & & Increased \\
\hline PMS/DMT ${ }^{\mathrm{a}}$ & 2924 & 2924 & 2922 & (C-H), stretching vibration of benzene & Increased \\
\hline $\mathrm{PMS} / \mathrm{DMT}^{\mathrm{a}}$ & 2852 & 2852 & 2852 & $\mathrm{C}-\mathrm{H}$ stretch in aldehydes & Increased \\
\hline PMS/DMT ${ }^{\mathrm{a}}$ & 1714 & ------- & 1714 & $\mathrm{C}=\mathrm{O}$ stretch, carboxylic acid & New Band \\
\hline $\mathrm{PMS} / \mathrm{DMT}^{\mathrm{a}}$ & 1645 & 1645 & 1337 & $\mathrm{C}=\mathrm{C}$ stretch & Decreased \\
\hline $\mathrm{PMS} / \mathrm{DMT}^{\mathrm{a}}$ & 1455 & 1455 & 1453 & $\mathrm{C}=\mathrm{O}$ stretch vibrations, Carboxylic acids-dimeric forms & Decreased \\
\hline PMS/DMT ${ }^{\mathrm{a}}$ & 1114 & 1114 & 1111 & & Increased \\
\hline $\mathrm{PMS} / \mathrm{DMT}^{\mathrm{a}}$ & 830 & 830 & 830 & Conjugated double bond & Increased \\
\hline PMS/DMT ${ }^{\mathrm{a}}$ & 671 & 671 & ----- & $=\mathrm{C}-\mathrm{H}$ bending & Disappear \\
\hline
\end{tabular}

${ }^{\mathrm{a}} \mathrm{PMS}$ blended with $4 \%$ DMT plasticizer. 
3) The Spectra of PMS showed a broad band between $2960 \mathrm{~cm}^{-1}$ and $2850 \mathrm{~cm}^{-1}$, with two breaded shoulders at $2924 \mathrm{~cm}^{-1}$ and $2854 \mathrm{~cm}^{-1}$, assigned to the (C-H), stretching vibration of benzene, was found to increase in its intensity with the increase of time of irradiation. Such observation suggests that the photodegradation of PMS involves the oxidation of benzene rings [13].

4) In the complex region of the $\mathrm{C}-\mathrm{O}$ stretch and $\mathrm{C}-\mathrm{O}-\mathrm{H}$ bend vibrations, an increase in the absorbance is observed throughout the increase in irradiation times of the polymer, which becomes higher in the case of blended polymer. Well-defined maxima appear in the Spectra, as shown in Table 2. Major increases at $1455 \mathrm{~cm}^{-1}$, and $1114 \mathrm{~cm}^{-1}$ could suggest the formation of mono-substituted benzene rings [13].

5) The presence of the absorption band at $830 \mathrm{~cm}^{-1}$, as can be seen in Figure 10, and its absence in Figure 9, may suggest the formation of conjugated double bond sequences in the main polymer chain during the irradiation process. The same band was observed by Grassie and Weir [6], on photo-oxidation of polystyrene.

\section{Conclusions}

Based on the obtained values of fluorescence quenching for the irradiated plasticized and non-plasticized PMS solid films, the following conclusions can be summarized as follows:

1) Irradiation of PMS films in presence of air led to important modification of UV absorption spectra of the exposed sample. Photo-oxidation processes of polymeric chains provoked an important increase in absorption and a change in the shape of absorption spectra.

2) It was found that irradiation of PMS films at $265 \mathrm{~nm}$ resulted in a decrease in the intensity of excimer fluorescence and changes in the shape of the fluorescence spectra. This indicates that there is a possibility of photodegradation in the polymeric chains.

3) Irradiation of PMS and blended PMS films in presence of air led to important modification to the FT-IR spectra. Photo-oxidation of blended polymeric chains, showed an increase in the intensity of absorption with the increase in the amount of added plasticizer, and an increase in the intensity of a new absorption bands at about (1645, and $1714 \mathrm{~cm}^{-1}$ ). This is an indication of a decrease in the stability of polymeric chains in presence of added plasticizer molecules.

4) A new mathematical relationship was applied, which makes it possible to evaluate the efficiency of the photo-quenching processes for blended and pure PMS, from which the photo-quenching rate constants $\left(k_{P Q}\right)$ and the efficiency of excimer quenching were calculated. The later can be used as an indication for the efficiency of photo degradation of irradiated PMS.

\section{References}

[1] Bertini, F., Audisio, G. and Kiji, J. (1995) Thermal Degradation of Chlorinated Polystyrenes. Journal of Analytical and Applied Pyrolysis, 28, 205-217. http://dx.doi.org/10.1016/0165-2370(93)00774-H

[2] Lucas, P.C. and Porter, R.S. (1989) Auto Inhibition in Polystyrene Photo-Oxidation. Polymer Degradation and Stability, 26, 203-208. http://dx.doi.org/10.1016/0141-3910(89)90073-6

[3] Ranby, B. and Rabek, J.F. (1974) Studies on the Photo-Oxidation Mechanism of Polymers. I. Photolysis and Photo-Oxidation of Polystyrene. Journal of Polymer Science, Polymer, Chemistry Edition, 12, 273-294. http://dx.doi.org/10.1002/pol.1974.170120203

[4] Torikai, A., Takeuchi, A. and Fueki, K. (1986) The Effect of Temperature on the Photodegradation of Polystyrene. Polymer Degradation and Stability, 14, 367-375. http://dx.doi.org/10.1016/0141-3910(86)90040-6

[5] Weir, N.A. (1978) Reactions of Hydroxyl Radical with Polystyrene. European Polymer Journal, 14, 9-14. http://dx.doi.org/10.1016/0014-3057(78)90144-1

[6] Grassie, N. and Wier, N.A. (1965) The Photo-Oxidation of Polymer. II. Photolysis of Polystyrene. Journal of Applied Polymer Science, 9, 975-986. http://dx.doi.org/10.1002/app.1965.070090315

[7] Al Ani, K.E. and Ramadhan, A.E. (2008) Photodegradation of Plasticized Poly (Para-Substituted Styrene) in Solution. Polymer Degradation and Stability, 93, 1590-1596. http://dx.doi.org/10.1016/j.polymdegradstab.2008.04.010

[8] Al Ani, K.E. and Ramadhan, A.E. (2010) Plasticization Effect on the Photodegradation of Poly (4-Chlorostyrene) and Poly (4-Bromostyrene) Films. Materials Sciences and Applications, 1, 358-368. http://dx.doi.org/10.4236/msa.2010.16052

[9] Al Ani, K.E. and Ramadhan, A.E. (2010) Study of the Influence of UV-irradiation on the Photodegradation of Plasti- 
cized Poly (Para-Tert-Butylstyrene) Films. International Journal of Material Research, 101, 1554-1562. http://dx.doi.org/10.3139/146.110434

[10] Al Ani, K.E. and Suleiman, A.M. (2007) Substituent Effect on Fluorescence Quenching of Polystyrene Derivatives by Polymeric Plasticizers. Journal of Photochemistry and Photobiology, A, Chemistry, 188, 177-184. http://dx.doi.org/10.1016/j.jphotochem.2006.12.010

[11] Al Ani, K.E. and Hawi, M.A. (2009) Effect of Plasticization on the Photodegradation of Poly (Para-Methoxystyrene) Films. Journal of Material Science, 44, 2674-268. http://dx.doi.org/10.1007/s10853-009-3350-X

[12] Al Ani, K.E. and Anabtawi, M. (2012) UV-Irradiation Effect on the Photodegradation of Plasticized Poly (Ortho, Meta, and Para-Fluorostyrene) Isomers in Solid Films. International Journal of Chemistry, 4, 62-84. http://dx.doi.org/10.5539/ijc.v4n5p62

[13] Bera, M., Rivaton, A., Gandon, G. and Gardette, J.L. (2000) Photo-oxidation of Poly (P-Xylene). European Polymer Journal, 36, 1753-1764. http://dx.doi.org/10.1016/S0014-3057(99)00258-X

[14] David, C., Baeyens-Volant, D., Delaunois, G., Lu-Vinh, Q., Piret, W. and Geuskens, G. (1978) Photooxidation of Polymers-III Molecular Weight Changes in the Photolysis and Photooxidation of Polystyrene). European Polymer Journal, 14, 501-507. http://dx.doi.org/10.1016/0014-3057(78)90037-X

[15] White, K.R. and Shyichuk, A.V. (2007) Effect of Stabilization on Scission and Cross-Linking Rate Changes during Photo-Oxidation of Polypropylene. Polymer Degradation and Stability, 92, 2095-2101. http://dx.doi.org/10.1016/j.polymdegradstab.2007.07.013

[16] McNeill, C. and Coskun, M. (1987) Structure and Stability of Halogenated Polymers: Part 2-Chain-Chlorinated Polystyrene. Polymer Degradation and Stability, 18, 213-224. http://dx.doi.org/10.1016/0141-3910(87)90002-4

[17] Mailhot, B., Jarroux, N. and Gardette, J.L. (2000) Comparative Analysis of the Photo-Oxidation of Polystyrene and Poly ( $\alpha$-Methylstyrene). Polymer Degradation and Stability, 68, 321-326. http://dx.doi.org/10.1016/S0141-3910(00)00016-1

[18] Rabek, J.F. (1995) Polymer Photodegradation, Mechanisms and Experimental Methods. Chapman and Hall, London. http://dx.doi.org/10.1007/978-94-011-1274-1

[19] Millan, M.D., Locklin, J., Fulghum, T., Baba, A. and Advincula, R.C. (2003) Polymer Thin Film Photodegradation and Photochemical Cross-Linking FT-IR Imaging Evanescent Waveguide Spectroscopy, and QCM Investigation. Polymer, 46, 5556-5568. http://dx.doi.org/10.1016/j.polymer.2005.05.050

[20] Rao, C.N.R. (1975) Ultraviolet and Visible Spectroscopy. 3rd Edition, Butterworth, London.

[21] Tamai, T., Hashida, I., Ichinose, N., Kawanishi, S., Inoue, H. and Mizuno, K. (1996) UV-Irradiation of Thin Film of Polystyrene Derivatives: Formation of Carboxylic Group and Cross-Linking from 4-Trimethylsilylmethyl Substituent. Polymer, 37, 5525-5528. http://dx.doi.org/10.1016/S0032-3861(96)00438-7

[22] Geuskens, G., Bastin, P., Lu-Vinh, Q. and Rens, M. (1981) Photo-Oxidation of Polymers: Part IV-Influence of the Processing Conditions on the Photo-Oxidation Stability of Polystyrene. Polymer Degradation and Stability, 3, 295-306. http://dx.doi.org/10.1016/0141-3910(81)90025-2

[23] Tse, K.C., Ng, F.M. and Yu, K.N. (2006) Photo-Degradation of DAVC by UV-Radiation at Various Wavelengths. Polymer Degradation and Stability, 91, 2380-2388. http://dx.doi.org/10.1016/j.polymdegradstab.2006.03.017

[24] Mailhot, B. and Gardette, J.L. (1992) Polystyrene Photooxidation-1: Identification of the IR-Absorbing Photoproducts Formed at Short and Long Wavelength. Macromolecules, 25, 4119-4126. http://dx.doi.org/10.1021/ma00042a012

[25] Geuskens, G., Baeyens-Volant, D., Delaunois, G., Lu-Vinh, Q., Piret, W. and David, C. (1978) Photo-Oxidation of Polymers-I: A Quantitative Study of the Chemical Reactions Resulting from Irradiation of Polystyrene at $253.7 \mathrm{~nm}$ in the Presence of Oxygen. European Polymer Journal, 14, 291-297. http://dx.doi.org/10.1016/0014-3057(78)90051-4

[26] Ranby, B. and Rabek, J.F. (1975) Photodegradation of Polymers. Wiley, New York, 165.

[27] Torikai, A., Takeuchi, T. and Fueki, K. (1983) Photodegradation of Polystyrene and Polystyrene Containing Benzophenone. Polymer Photochemistry, 3, 307-320. http://dx.doi.org/10.1016/0144-2880(83)90038-6

[28] Kowal, J. and Nwakowska, M. (1982) Photo-Oxidation of Polystyrene in Dichloromethane Solvent. Polymer, 23, 281282. http://dx.doi.org/10.1016/0032-3861(82)90316-0

[29] Torikai, A., Kobatake, T., Okisaki, F. and Shuyama, H. (1995) Photodegradation of Polystyrene Containing FlameRetardant Wavelength Sensitivity and Efficiency of Degradation. Polymer Degradation and Stability, 50, 261-267. http://dx.doi.org/10.1016/0141-3910(95)00143-3

[30] Choi, W.M., Jung, I.D., Sik, C. and Cho, W. (1998) Syntheses and Properties of Photodegradable Polystyrene-Containing Carbonyl Group. Journal of Applied Polymer Science, 67, 1237-1242. http://dx.doi.org/10.1002/(SICI)1097-4628(19980214)67:7<1237::AID-APP11>3.0.CO;2-Z 
[31] Ramadhan, A.E., Ahmed, R.K. and Al Ani, K.E. (2006) Thermal Effect and Quenching of Exciplex Fluorescence of Polystyrene Derivatives by Dimethyl Terephthalate in Solid Films. Polymer Journal, 38, 355-363. http://dx.doi.org/10.1295/polymj.38.355

[32] Stivala, S.S., Kimum, J. and Reich, L. (1983) Degradation and Stability of Polymers. Ed. Jellinek. H.G., Elsevier, Amsterdam, 1-66..

[33] Weir, N.A. (1982) In: Grassie, N., Ed., Developments in Polymer Degradation, Applied Science, London, 143.

[34] Zhang, Z.F., Hu, X.Z. and Luo, Z.B. (1996) Wavelength Sensitivity of Photo-Oxidation of Polypropylene. Polymer Degradation and Stability, 51, 93-97. http://dx.doi.org/10.1016/0141-3910(95)00210-3

[35] Otocka, E.P., Curran, S. and Porter, R.S. (1983) Photo-Oxidation of Polystyrene: Irradiation at 254 and 365 nm. Journal of Applied Polymer Science, 28, 3227-3233. http://dx.doi.org/10.1002/app.1983.070281017

[36] Weir, N.A. and Milkie, T.H. (1979) Photochemistry of Ring-Substituted Polystyrenes. II. Photolysis of Poly ( $p$-Fluoro, p-Chloro, and p-Bromostyrene). Journal of Polymer Science: Polymer Chemistry Edition, 17, 3735-3749. http://dx.doi.org/10.1002/pol.1979.170171129

[37] Subramanian, K. (2001) Photodecomposition of Poly(Styrene Peroxide) in Vinyl Monomers and Structural Features of the Formed Polymers. European Polymer Journal, 37, 66-54. http://dx.doi.org/10.1016/S0014-3057(01)00297-X

[38] Stokes, S. and Fox, R.B. (1962) Photolysis of Poly- $\alpha$-Methylstyrene. Journal of Polymer Science, 56, 507-517. http://dx.doi.org/10.1002/pol.1962.1205616422

[39] Zuev, V.V., Zgonnik, P.V., Turkova, L.D. and Shibaev, L.A. (1999) Thermal Degradation of Poly (p-Nitrostyrene). Polymer Degradation and Stability, 63, 15-17. http://dx.doi.org/10.1016/S0141-3910(98)00055-X

[40] Zuev, V.V., Bertini, F. and Audisio, G. (2001) Thermal Degradation of Para-Substituted Polystyrenes. Polymer Degradation and Stability, 71, 213-221. http://dx.doi.org/10.1016/S0141-3910(00)00113-0

[41] Lacoste, J., Carlson, D.J., Falicki, S. and Wiles, M.D. (1991) Polyethylene Hydroperoxide Decomposition Products. Polymer Degradation and Stability, 34, 309-323. http://dx.doi.org/10.1016/0141-3910(91)90125-B

[42] Subramanian, K. (2002) Photodecomposition of Poly (Styrene Peroxide). European Polymer Journal, 38, 1167-1173. http://dx.doi.org/10.1016/S0014-3057(01)00297-X

[43] Tovborg Jensen, J.P. and Kops, J.J. (1981) Energy Transfer in Connection with the Photo-Oxidation of Polystyrene and Its Blends with Poly(2,6-Dimethyl-1,4-Phenylene Oxide). Journal of Polymer Science: Polymer Chemistry Edition, 19, 2765-2771. http://dx.doi.org/10.1002/pol.1981.170191112

[44] Fields, E.K. and Meyerson, S. (1975) In: Williams, G.H., Ed., Advances in Free-Radical Chemistry, 5, Elek Science, London, 101.

[45] Kaczmarek, H. (1995) Photodegradation of Polystyrene and Poly(Vinyl Acetate) Blends. II. Irradiation of PS/PVAc Blends by Fluorescent Lamp. European Polymer Journal, 31, 1175-1184. http://dx.doi.org/10.1016/0014-3057(95)00095-X

[46] Kaczmarek, H. (1995) Photodegradation of Polystyrene and Poly(Vinyl Acetate) Blends-I. Irradiation of PS/PVAc Blends by Polychromatic Light. European Polymer Journal, 31, 1037-1042. http://dx.doi.org/10.1016/0014-3057(95)00094-1

[47] Al Ani, K.E., Al Barghouthi, M. and Buzour, M. (2006) Solvent Effect on Thermal Degradation of Plasticized ParaSubstituted Polystyrenes. Polymer Degradation and Stability, 91, 3252-3258. http://dx.doi.org/10.1016/j.polymdegradstab.2006.07.002

[48] Weir, N.A. (1982) In: Grassie, N., Ed., New Trends in the Photochemistry of Polymers, Applied Science, London, 207.

[49] Luengo, C., Allen, N.S., Edge, M., Wilkinson, A., Parellada, M., Barrio, J.A. and Santa, R. (2006) Photo-Oxidative Degradation Mechanisms in Styrene-Ethylene-Butadiene-Styrene (SEBS) Triblock Copolymer. Polymer Degradation and Stability, 91, 947-956. http://dx.doi.org/10.1016/j.polymdegradstab.2005.06.017 